\title{
Endothelin and Nitric Oxide Synthase in Lymphatic Endothelial Cells: Immunolocalization In Vivo and In Vitro
}

\author{
CARLA MARCHETTI, ${ }^{*}$ ANDREA CASASCO, ${ }^{1}$ AMALIA DI NUCCI, \\ MARCELLA REGUZZONI, ${ }^{1}$ SIMONE ROSSO, ${ }^{3}$ FRANCO PIOVELLA, ${ }^{3}$ \\ ALBERTO CALLIGARO, ${ }^{1}$ AND J ULIA M. POLAK ${ }^{4}$ \\ II stituto di I stologia ed E mbriologia Generale, University of Pavia, Pavia, I taly \\ 2/ stituto di F armacol ogia Medica, University of Pavia, Pavia, I taly \\ 3I stituto di Clinica Medica II, S. Matteo Hospital, University of Pavia, Pavia, I taly \\ ${ }^{4}$ Royal Postgraduate Medical School, Hammersmith Hospital, Histochemi stry Unit, \\ London, England
}

\begin{abstract}
Background: Endothelin (ET) is an endothelium-derived multifunctional peptide that produces a potent, long-lasting vasoconstriction. Nitric oxide (NO), besides being the most important endotheliumderived relaxant factor in blood vessels, is supposed to be involved in regulating the interactions among endothelium, adhesive molecules, and leukocytes.

Methods: We investigated the possible occurrence and distribution of ET and constitutive nitric oxide synthase (NOs), the enzyme that generates NO from L-arginine, in bovine lymphatic vessels and primary culture of lymphatic endothelium by using immunocytochemistry.

Results: Specific immunostaining with both ET and endothelial constitutive NOs antisera was detectable at light and electron microscopic levels in the endothelial cell layer of lymphatic vessels, whereas no immunostaining could be observed in the muscular and adventitial layers. The immunoreaction showed a diffuse pattern throughout the cytoplasm of endothelial cells. Primary cultures of endothelial cells isolated from lymphatic vessels also displayed cytoplasmic ET- and NOs-like immunoreactivities. The endothelial nature of cell monolayers was confirmed by the positive reaction to the von Willebrand factor, a reliable marker of endothelial cells, and by ultrastructural features of cultured cells.

Conclusions: These findings suggest that the endothelium is a major source of ET and NO in lymphatic vessels. Interestingly, the lymphatic endothelium maintains the capability of producing such vasoactive sustances also in vitro, thus suggesting that lymphatic endothelial cells in culture may be used in studies concerning the role of the endothelium in the generation of vasoactive molecules. According to previous functional studies, the occurrence of ET and NOs immunoreactivities in lymphatic vessel endothelium supports the view that lymphatic endothelium may play an important role in the regulation of lymphatic vascular tone and in the production of vascular contractile activity promoting lymph flow. Anat. Rec. 248:490-497, 1997. 1997 Wiley-Liss, Inc.
\end{abstract}

Key words: endothelin; nitric oxide; endothelium; lymphatic vessels; lymph flow; immunocytochemistry

Blood vascular endothelium releases vasoactive mediators that originally were called endothelium-derived relaxing factors (EDRF) and endothelium-derived contracting factors (EDCF) according to their action on the muscular wall. Subsequent studies have provided convincing evidence that endothelin (ET) and nitric oxide (NO) are responsible for most of the contracting activity and relaxing activity, respectively, by the regulation of vascular smooth muscle cells via paracrine mechanism
(Palmer et al., 1987; Yanagisawa et al., 1988; Vane et al., 1990; Moncada et al., 1991; Masaki et al., 1992; Moncada, 1992; Moncada and Higgs, 1993).

ET is a 21-amino-acid peptide that, besides being the most potent and long-acting vasoconstrictive peptide so

*Correspondence to: Prof. Carla Marchetti, Istituto di Istologia ed Embriologia Generale, via F orlanini, 10, I-27100 Pavia, I taly.

Received 28 October 1996; accepted 27 F ebruary 1997. 
far discovered, is able to exert several biological actions, including neuromodulation, stimulation of cell growth, and modulation of hormone release (Yanagisawa et al., 1988; Rubanyi and Parker Botelho, 1991; Masaki et al., 1992). NO is a free radical gas produced intracellularly through the conversion of L-arginine to $\mathrm{L}$-citrulline by the enzyme NO synthase (NOs). There is now evidence for multiple forms of this enzyme, all of which require $\mathrm{NicotinamideAdenine} \mathrm{Dinucleotide} \mathrm{Phos}$ phate Reduced (NADPH) as a cofactor (Moncada et al., 1991; F orstermann et al., 1991). One group of enzymes is constitutive and requires calcium and calmodulin as cofactors. The other group is inducible in response to cytokines or endotoxin and is calcium/calmodulin independent. Both constitutive and inducible isoforms occur in vascular endothelium (Moncada et al., 1991; Moncada, 1992). Under basal conditions, NO is supposed to be the most important regulator of vascular tone, and it is essential for maintaining normal vascuIar resistance (I gnarro et al., 1987; Palmer et al., 1987; Moncada and Higgs, 1993). Indeed, the inactivation of NOs causes vasoconstriction and long-lasting pressor response (Moncada et al., 1991; Berdeaux, 1993). Increasing evidence now exists that NO may exert other biological actions such as inhibition of platel et aggregation, attenuation of leukocytes and endothel ium interaction, and maintenance of the vascular permeability barrier (I gnarro, 1989; Kubes and Granger, 1992).

Lymph propulsion and return from the tissues are carried out by both passive and active driving mechanisms. The passive mechanism is caused by compression and suction of lymphatic vessels, resulting from extrinsic activities of the surrounding tissue. The passive driving system is probably the main mechanism of propulsion of the lymph in the initial lymphatics and in those collecting vessels with a thin smooth muscle layer. The active driving mechanism is due to intrinsic contractility of lymphatic vessels, promoted by the activity of the smooth muscle cells of thelymphatic wall (Ohhashi et al., 1980; Drake et al., 1985; Ohhashi, 1993). The existence of the active mechanism promoting the lymph flow induces the belief that local mediators could modulate smooth muscle cell toneand contractility in lymphatic vessels. Previous investigations have suggested that some vasoactive substances may modulate the contractility of the Iymphatic vessel wall (Dabney et al., 1988, 1991; F ortes et al., 1989; Dobbins et al., 1991; Dobbins and Dabney, 1991; Ferguson and DeFili ppi, 1994). Other studies have demonstrated that Iymphatic endothelial cells are able to rel ease vasodilator agents. These findings suggested the hypothesis that lymphati c vessel s may regulate their own vascular tone (Ohhashi and Takahashi, 1991; Bohlen and Lash, 1992; Ohhashi and Yokoyama, 1994).

Although ET-like immunoreactivity has been demonstrated in the lymphatic vessel wall, some discrepancies exist as to whether ET is localized only in the endothelial layer or also in the muscular layer (Ohkuma, 1991).

In the present study, we investigated the presence of ET and constituive NOs in lymphatic vessels and in cultured endothelial cells by immunocytochemical reactions.

\author{
MATERIALS AND METHODS \\ Collection of Lymphatic Vessels and Culture \\ of Lymphatic Endothelial Cells
}

Lymphatic vessels ( $\mathrm{n}=18$ ) were obtained from 10 bovine mesenteries from 2-3-year-old animals. The lymphatic vessel network was delineated by injecting a solution of $0.1 \%$ Evan's blue in phosphate buffered saline (PBS) into mesenteric lymph nodes. Some vessels $(n=10)$ were cut into small pieces and immediately fixed in $4 \%$ paraformal dehyde in $0.1 \mathrm{M}$ phosphate buffer, $\mathrm{pH}$ 7.3, at room temperature for $3 \mathrm{hr}$. The specimens were washed in 0.05 M Tris buffer, $\mathrm{pH} 7.4$, containing $0.1 \mathrm{M} \mathrm{NaCl}(0.15 \mathrm{M}$ Tris buffered saline; TBS) and $15 \%$ sucrose overnight, embedded in Tissue Tek II OCT (Miles, Naperville, IL), rapidly frozen in isopentane cooled by liquid nitrogen, and cut in a cryostat.

Endothelial cells for cultures were obtained by collagenase digestion from other isolated lymphatic vessels $(n=8)$. Dye-filled vessels were cannulated at both ends and washed with normal saline solution and incubated at $37^{\circ} \mathrm{C}$ for $10 \mathrm{~min}$. The vessels were then drained with culture medium TC 199 containing Earle's salts and L-glutamine and supplemented with $20 \%$ fetal calf serum, $\mathrm{NaHCO}_{3} 2.2 \mathrm{mg} / \mathrm{ml}$, penicillin $200 \mathrm{U} / \mathrm{ml}$, and streptomycin $200 \mathrm{mg} / \mathrm{ml}$. After washing, the vessels were incubated with $0.2 \%$ collagenase in saline solution at $37^{\circ} \mathrm{C}$ for $5 \mathrm{~min}$. The fluid was collected and placed in Costar well plates containing coverslips for cell cultures. Cells were grown at $37^{\circ} \mathrm{C}$ in a humidified incubator with air and $5 \% \mathrm{CO}_{2}$. The cells were fixed for $5 \mathrm{~min}$ in $4 \%$ paraformaldehyde in $0.1 \mathrm{M}$ phosphate buffer and washed in TBS before immunostaining.

\section{Light Microscopy Immunocytochemistry}

Sections of lymphatic vessels (at least 5/vessel; $N=$ 50) and primary cultures $(n=8)$ of lymphatic vessel cells were trated for the immunocytochemical reaction to detect ET and endothelial constitutive NOs by indirect immunofluorescence and immunoperoxidase (Polak and Van Noorden, 1986). The demonstraction of the endothelial nature of cultured cells was also performed by the immunolocalization of the von Willebrand factor (vWf).

All the samples were treated with $0.3 \%$ Triton $X 100$ in TBS for $1 \mathrm{~min}$ and rinsed in TBS thoroughly. Samples for immunoperoxidasereaction were al so incubated with $0.3 \%$ hydrogen peroxide in TBS for $30 \mathrm{~min}$ to remove endogenous peroxidase activity. Normal goat serum, diluted to 1:20 in TBS, was applied for $30 \mathrm{~min}$ at room temperature to reduce possible background staining. The samples were then incubated overnight at $4^{\circ} \mathrm{C}$ with rabbit polyclonal antisera to $\mathrm{ET}, \mathrm{NOs}$, and von Willebrand protein (dilutions between 1:50 and 1:1,000). The samples were washed in TBS, incubated with either tetramethylrhodamine isothiocyanate (TRITC), conjugated or biotinylated goat anti-rabbit I gG, diluted to 1:100 in TBS for $30 \mathrm{~min}$, and then washed in TBS.

The samples were stained with TRITC antibodies and mounted with TBS glycerol (1:1). The samples labeled with biotinylated antibodies were incubated with streptavidin-biotinylated peroxidase complexes diluted to 1:200 in TBS for $1 \mathrm{hr}$ at room temperature. The samples were washed in TBS, and peroxidase was 
visualized by incubation with $0.03 \% 3,3$ '-diaminobenzidine tetrahydrochloride (DAB) solution in $0.05 \mathrm{M}$ Tris$\mathrm{HCl}, \mathrm{pH} 7.4$, to which $0.02 \%$ hydrogen peroxide was added before use.

Some sections and cell monolayers were lighly counterstained with haematoxylin and mounted in DPX for light microscope examinations.

\section{Conventional Electron Microscopy and Electron Microscopy Immunocytochemistry}

Cultures $(n=8)$ of lymphatic vessel cells were routinely processed for electron microscopy to assess the endothelial nature of cultured cells. Briefly, cell culture monolayers were fixed with $2.5 \%$ glutaraldehyde in $0.1 \mathrm{M}$ sodium cacodylate buffer, $\mathrm{pH} 7.4$, for 30 $\min$ at $37^{\circ} \mathrm{C}$ and for $30 \mathrm{~min}$ at $4^{\circ} \mathrm{C}$. The monolayers were postfixed in $1 \% \mathrm{OsO}_{4}$ in $0.2 \mathrm{M}$ collidine buffer, $\mathrm{pH}$ 7.4, for $1 \mathrm{hr}$ at $4^{\circ} \mathrm{C}$, dehydrated, and embedded in epoxy resin. Ultrathin sections $(80 \mathrm{~nm})$ were cut perpendicularly to the monolayer plane and countrasted with uranyl acetate and lead citrate for transmission electron mi croscope observations.

Small pieces of lymph vessels $(n=8)$ were fixed in $4 \%$ paraformal dehyde in 0.1 M phosphate buffer, pH 7.3, at room temperature for $6 \mathrm{hr}$. After washing in $0.05 \mathrm{M}$ Tris buffer, $\mathrm{pH} 7.4$, containing $0.1 \mathrm{M} \mathrm{NaCl}$ (TBS), the samples were processed for the immunocytochemical identification of ET and NOs immunoreactivities by using a preembedding immunoperoxidase technique, as described previously (Sexton et al., 1995). The samples were processed according to the protocol described for the localization of ET and NOs immunoreactivities at light microscopy. After peroxidase visualization with the DAB solution, the samples of Iymphatic vessels were fixed in $2.5 \%$ glutaraldehyde, postfixed in $1 \% \mathrm{OsO}_{4}$, and routinely embedded in epoxy resin. I mmunostained lymphatic vessels were cut transversally to obtain semithin and ultrathin sections. At least three sections per lymphatic vessel were observed.

\section{Antisera and Specificity Controls of the Immunocytochemical Reactions}

The antisera against synthetic ET-1 and endothelial constitutive NOs were raised in rabbits and have been characterized el sewhere (Yoshizawa et al., 1990; Casasco et al., 1991, 1993; Springall et al., 1991, 1992; Buttery et al., 1994). Pertinent specificity tests were performed, including adsorption of the specific antisera with re lated and unrelated antigens, omission of the first layer, and substitution of an inappropriate antiserum or a nonimmune serum for the specific primary antisera (Polak and Van Noorden, 1986).

As for ET antiserum, immunostaining was prevented by adsorption of antiserum with synthetic ET-1, -2 , or -3 (10 nmol in $1 \mathrm{ml}$ antiserum diluted 1:700 in TBS), indicating that the antiserum cross reacts with different ET isoforms.

NOs antiserum was raised against a synthetic 15residue peptide, based on deduced amino acid sequences of CDNA encoding the bovine and human endothelial constitutive NOs (Lamas et al., 1992; Marsden et al., 1992). The peptide sequence was VTSRIRTQSFSLQER-C, corresponding to amino acids $1172-1186$ of the deduced amino acid sequence, with a cysteine residue at the $C$ terminus to assist coupling to carrier. This sequence represents a one that is identical between the bovine and human endothelial NOs (Lamas et al., 1992; Marsden et al., 1992) and has low homology with other isoforms of NOs $(<50 \%$ with rat brain NOs and virtually no homology with macrophage NOs). The peptide was coupled to maleimide-activated key-hole limpet hemocyanin and used to immunize rabbits.

The antiserum to human von Willebrand protein and the secondary antibodies were purchased from Dakopatts (Glostrup, Denmark). Biotinylated probes were purchased from Amersham I nternational (Amersham, England).

\section{RESULTS \\ Immunocytochemistry}

ET and NOs immunoreactivities were detectable within endothelial cells of the isolated lymphatic vessels at both light and el ectron microscopic levels (Figs. $1 a \& 1 b$ and $2 a \& 2 b)$. The immunostaining was continuous along the endothelial layer. We saw no specific immunostaining in the muscular or adventitial layers with ET or NOs antisera in any of the sections examined.

In addition, lymphatic vessel endothelial cells in culture were immunoreactive with ET and NOs antisera (Fig. 3a \& 3b). The immunostaining, although diffuse throughout the cytoplasm, appeared more intense in the perinuclear portion of the cytoplasm. Cultured cells werealso positive for the demonstraction of vWf. The reaction showed a granular pattern within the cytoplasm (not shown).

In control samples that were not incubated with primary antisera, no immunostaining could be observed (Fig. 3c).

\section{Electron Microscopy}

At the ultrastructural level, Iymphatic endothelial cells exibited a flattened shape with a subtle profile (Fig. 4a). The cells were joined to one another by overlappings or interdigitations of the cellular edges. The cytoplasm, particularly in the perinuclear regions (Fig. 4b), contained rough endopl asmic reticulum cisternae, ribosomes, mitochondria, filaments, vacuoles, and vesicles. Moreover, it usually presented Weibel-Palade bodies, the cytoplasmic organelles characteristic of endothelial cells.

\section{DISCUSSION}

The present study demonstrates the occurrence and distribution of $\mathrm{ET}$ and constitutiveNOs immunoreactivities in the endothelium of lymphatic vessels. Because ET and NOs immunoreactivities were observed in lymphatic endothelium both in vivo and in vitro, we propose that cultured lymphatic endothelial cells may be profitably employed in further studies to investigate the role of lymphatic endothelium in the generation of vasoactive molecules.

To date, the exact localization of ET in lymphatic vessel walls has not been completely satisfactory (Okhuma, 1991). Our data confirm the occurrence of ET in the lymphatic vascular wall and provide evidence that this peptide is produced exclusivel y by the endothe lial cell layer. Lymphatic endothelial cells maintain their positivity to ET reaction when removed from the 

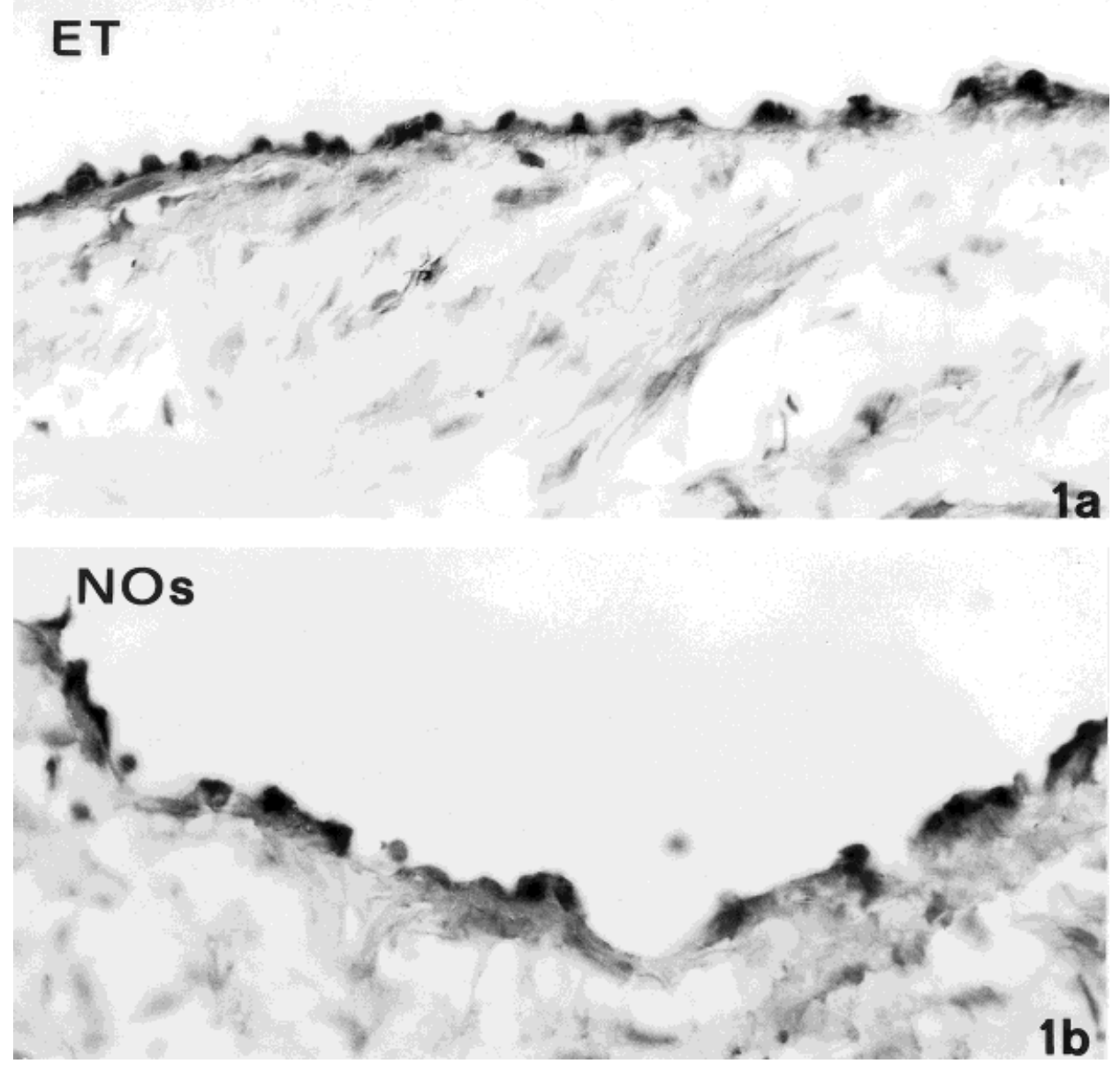

Fig. 1. I mmunohistochemical localization of (a) endothelin (ET) and (b) endothelial constitutive nitric oxide synthase (NOs) immunoreactivities in isolated bovine lymphatic vessels. The immunostaining is confined to the endothelial layer. I mmunoperoxidase method. $\times 800$.

vascular wall and cultured, as it has been demonstrated for blood vessel endothelium (Nakamura et al., 1990; L oesch et al., 1991). Our data are at variance with those reported by Ohkuma (1991) who also found ET immunoreactivity in the muscular layer of Iymphatic and blood vessels. Indeed, ET immunoreactivity has been revealed by using immunocytochemistry in different cell types (e.g., neurons, epithelial cells, macrophages), and the possible production of ET by smooth muscle cells in vitro has been reported (Resink et al., 1990). However, according to previous morphological studies, we never found ET immunoreactivity or mRNA in smooth muscle cells of any organ in vivo (MacCumber et al., 1989; Casasco et al., 1991, 1993; Giaid et al., 1991a,b; Springall et al., 1991).

Previous physiological studies have shown that lymphatic vessels constrict in response to exogenous ET, thus suggesting that this peptide may contribute to the control of lymph flow by affecting lymphatic vessels contractility (Dobbins and Dabney, 1991). The occurrence of ET immunoreactivity within lymphatic endothelial cells supports the view that lymphatic vessels may modulate with a self-mechanism for their own contractility, thus promoting the active driving mechanism for lymph flow (Ohhashi, 1993).
The detection of constitutive NOs immunoreactivity in lymphatic vessel endothelial cells in situ and in cultured endothelial cells isolated from lymphatic vessels strongly suggests that these cells are able to produce NO. Previous studies have suggested that this molecule might play a pivotal role in the molecular mechanisms that regulate lymphatic vessel tone and lymph flow (Ohhashi and Takahashi, 1991; Ohhashi and Yokoyama, 1994). The antiserum used in our experiments to reveal NOs was raised against the endothelial constitutive isoform of the enzyme. Indeed, we found specific immunostaining only within lymphatic endothelial cells, whereas the muscular and adventitial layers were negative to the reaction. Nevertheless, the inducible form of NOs has been localized in smooth muscle cells (for a review, see Moncada, 1992). Therefore, the possibility that smooth muscle cells of the lymphatic vessels are also able to produce the inducible isoform of NOs cannot be excluded.

A relationship between NO synthesis and changes in vascular permeability has been observed in blood vessels (Kubes and Granger, 1992). It has been also observed that the inactivation of NO by superoxide may be an important event at the onset of inflammation when leukocyte extravasation occurs (Ohhashi and 

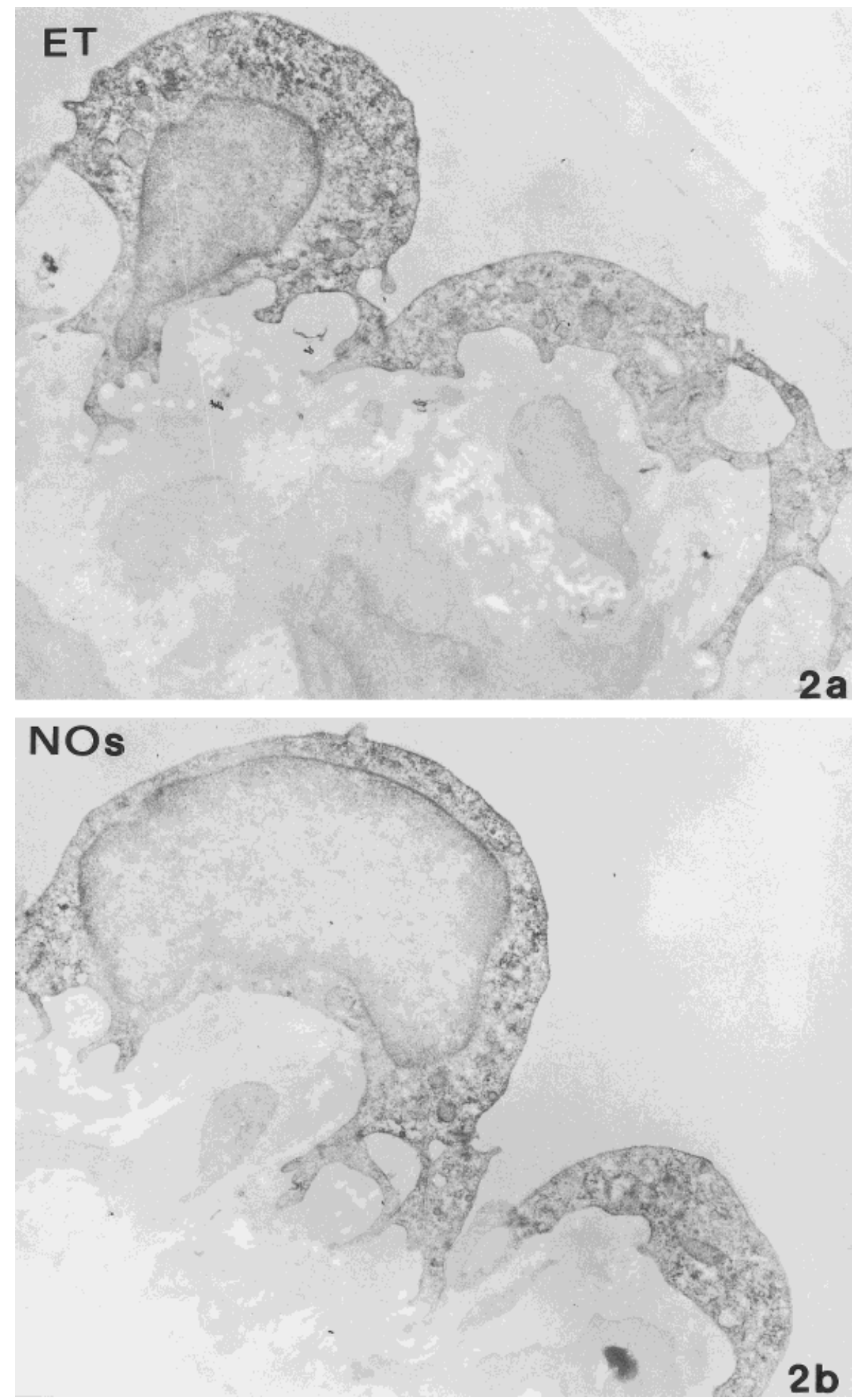

Fig. 2. Electron microscopical localization of (a) endothelin (ET) and (b) endothelial constitutive nitric oxide synthase (NOs) immunoreactivities in isolated bovine lymphatic vessels. The electron-dense

Yokoyama, 1994). Moreover, a correlation in vivo be tween decreased NO synthesis and expression of Pselectin, an adhesive molecule mediating the adhesion of platelets and neuthrophyls to blood endothel ium, has reaction product is detectable throughout the cytoplasm of endothelial cells. The nuclei of the endothelial cells and the cells underlying the endothelium appear negative. I mmunoperoxidase method. $\times 9,750$.

been described (Davenpeck et al., 1994). Because Psel ectin has been shown to occur in lymphatic endothelium (Marchetti et al., 1995; Di Nucci et al., 1996), it may be tentatively hypothesized that NO production by 

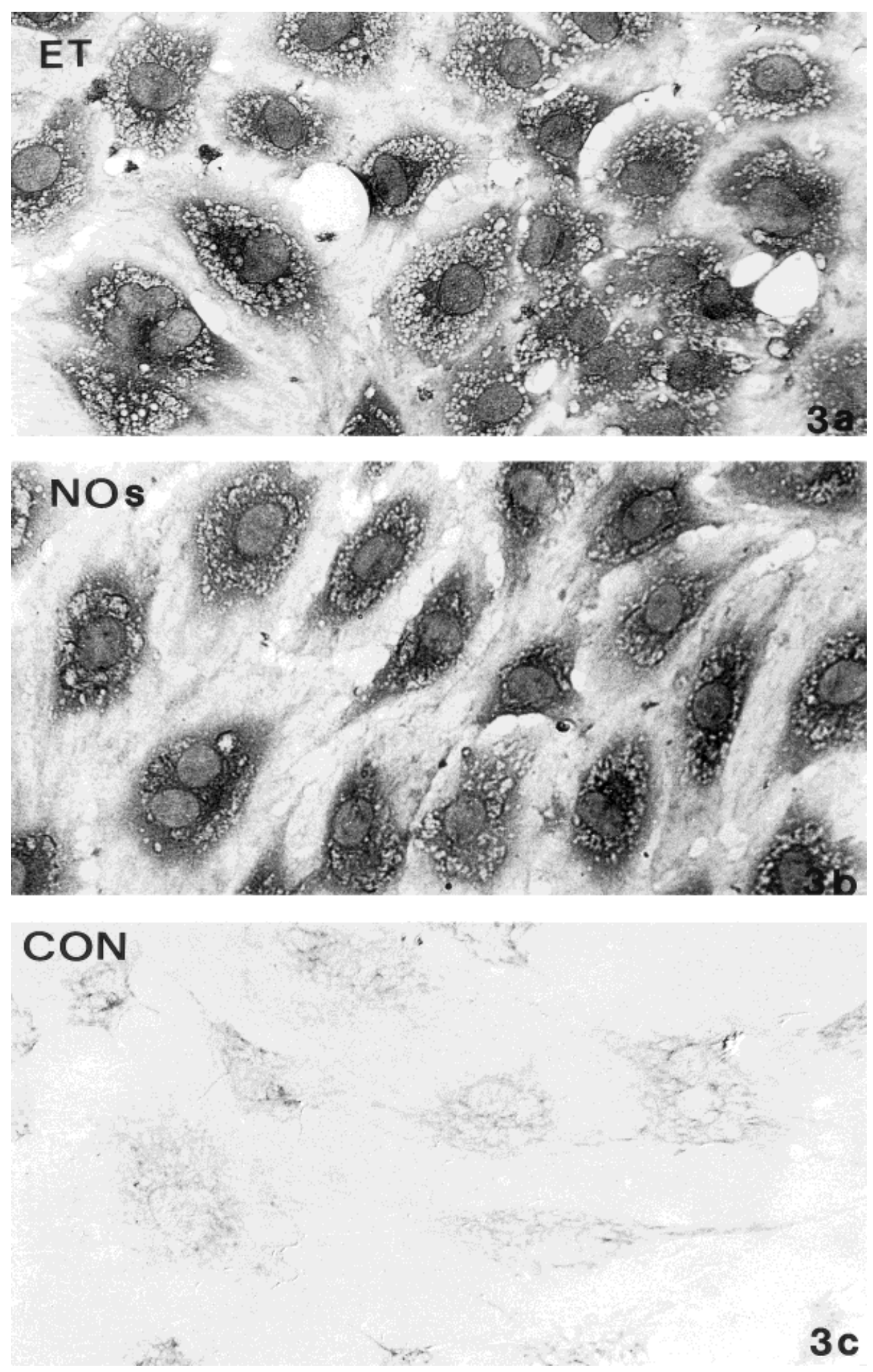

Fig. 3. Immunocytochemical localization of (a) endothelin (ET) and (b) endothelial constitutive nitric oxide synthase (NOs) immunoreactivities in cultured cells from lymphatic endothelium. Strong immuno-

endothelial NOs may also influence P-selectin activity in lymphatic vessels. This aspect might be important in the mechanisms that regulate the leukocyte adhesion to endothelial cells and extravasation. staining is detectable within the cytoplasm of cultured cells. c: In cultures used as a control of the immunoreaction (CON), no specific staining is visible. I mmunoperoxidase method. $\times 500$.

Taken together, our immunocytochemical findings suggest the existence in lymphatic endothelial cells of both vasoconstrictor and vasodilator factors, namely ET and NO, respectively, that may be involved in the 

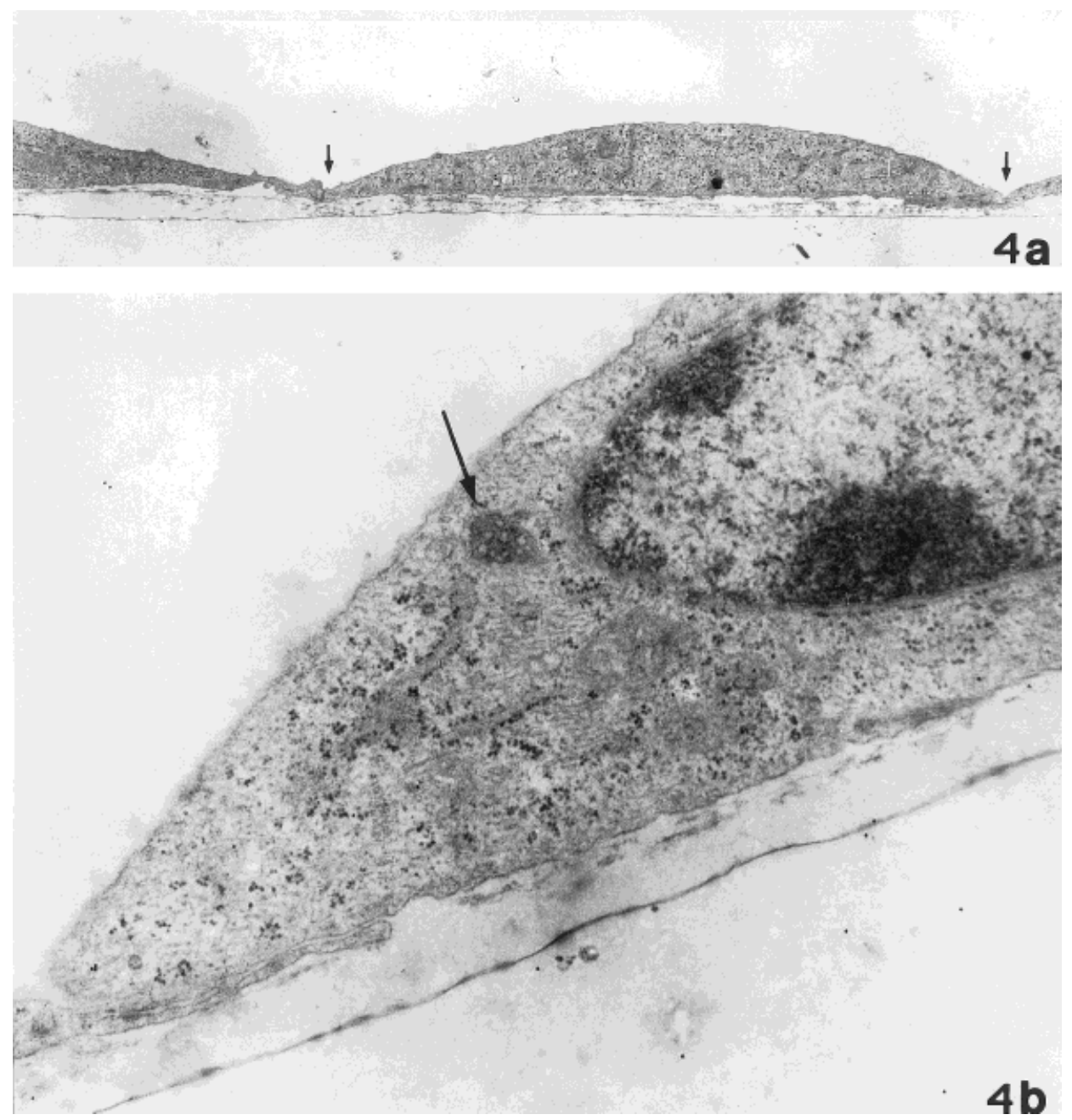

Fig. 4. Electron micrographs showing cultured lymphatic endothel ial cells sectioned perpendicularly to the monolayer plane. The contiguous endothelial cells are joined by overlappings of the cellular edges $(\mathbf{a}, \rightarrow)$. A Wei bel-Palade body $(\mathbf{b}, \rightarrow)$ is recognizable in the perinuclear region. $\times 4,000$ in $a, \times 20,000$ in $b$.

regulation of contractile activity of the vessel. Through these and probably other factors, the lymphatic vessels have the possibility to not only control the vascular tone but also produce and regulate the contractile activity necessary to promote the lymph flow according to the active driving mechanism. In line with this view, muscular tone has been shown to play an important role in the regulation of spontaneous contractions in lymphatic vessels (Ferguson and DeFilippi, 1994; Ohhashi and Yokoyama, 1994). However, because significant differences exist among the vessels of different organs with regard to the thickness of the muscular layer of the vascular wall, it is reasonable to presume that different vessels may have different capacities to respond to vasoactive factors.

\section{LITERATURE CITED}

Berdeaux, A. 1993 Nitric oxide: An ubiquitous messenger. Fund. Clin. Pharmacol., 7:401-411.

Bohlen, H.G., and G. Lash 1992 Intestinal lymphatic vessels release endothelial-dependent vasodilators. Am. J . Physiol., 262:H813$\mathrm{H} 818$.

Buttery, L.D.K., A. McCarthy, D.R. Springall, M.H.F. Sulliva, M.G. Elder, T. Michel, and J.M. Polak 1994 Endothelial nitric oxide synthase in the human placenta: Regional distribution and proposed regulatory role at the feto-maternal interface. Placenta, $15: 257-265$

Casasco, A., A. Calligaro, M. Casasco, D.R. Springall, P. Tenti, C. Marchetti, P. Poggi, and J .M. Polak 1991 Immunohistochemical localization of endothelin-like immunoreactivity in human tooth germ and mature dental pulp. Anat. Embryol., 183:515-520.

Casasco, A., M. Benazzo, M. Casasco, A. I caro Cornaglia, D.R. Springall, A. Calligaro, E. Mira, and J.M. Polak 1993 Occurrence, distribution and possible role of the regulatory peptide endothelin in the nasal mucosa. Cell Tissue Res., 274:241-247.

Dabney, J .M., M.J. Buehn, and D.E. Dobbins 1988 Constriction of lymphatics by catecholamines, carotid occlusion or hemorrhage Am. J. Physiol., 255:H514-H524.

Dabney, J.M., M.J . Buehn, and D.E. Dobbins 1991 Perfused prenodal lymphatics are constricted by prostaglandins. Am. J. Physiol., 260:H1-H5.

Davenpeck, K.L., T.W. Gauthier, and A.M. Lefer 1994 Inhibition of endothelial-derived nitric oxide promotes P-selectin expression and actions in the rat microcirculation. Gastroenterology, 107: $1050-1058$.

Di Nucci, A., C. Marchetti, S. Serafini, and F. Piovella 1996 P-selectin and von Willebrand factor are localized in bovine lymphatic vessels. Lymphology, 29:25-28.

Dobbins, D.E., and J.M. Dabney 1991 Endothelin-mediated constriction of prenodal lymphatic vessels in the canine forelimb. Regul. Peptides, 35:81-91. 
Dobbins, D.E., M.J. Buehn, and J .M. Dabney 1991 Constriction of perfused lymphatics by acetylcholine, bradykinin and histamine. Microcirc. Endoth. Lymph., 6:409-425.

Drake, R., M. Giesler, G. Laine, J . Gabel, and T. Hansen 1985 Effect of outflow pressure on lung lymph flow in unanesthetized sheep. J . Appl. Physiol., 58:70-76.

Ferguson, M.K., and V.J . DeF ilippi 1994 Nitric oxide and endothelium dependent relaxation in tracheobronchial lymph vessels. Microvasc. Res., 47:308-317.

Forstermann, U., H. Schmidt, J S. Pollok, H. Sheng, J .A. Mitchell, T.D. Warner, M. Nakane, and F. Murad 1991 I soforms of nitric oxide synthase. Characterization and purification from different cell types. Biochem. Pharmacol., 42:1849-1857.

Fortes, Z.B., R. Scivoletto, and J. Garcia-Leme 1989 Endothelin-1 induces potent constriction of Iymphatic vessels in situ. Eur. J . Pharmacol., 170:69-73.

Giaid, A., S.J. Gibson, M.T. Herrero, S. Gentleman, S. Legon, M. Yanagisawa, T. Masaki, N.B.N. I brahim, G.W. Roberts, M.L. Rossi, and J.M. Polak 1991a Topographical localisation of endothelin mRNA and peptide immunoreactivity in neurones of the human brain. Histochemistry, 95:303-314.

Giaid, A., J .M. Polak, V. Gaitonde, Q.A. Hamid, G. Moscoso, S. Legon, D. Uwanogho, M. Roncalli, O. Shinmi, T. Sawamura, S. Kimura, M. Yanagisawa, T. Masaki, and D.R. Springall 1991b The distribution of endothelin-like immunoreactivity and mRNA in the developing and adult human lung. Am. J . Resp. Cell Mol. Biol., 4:50-58

I gnarro, L.J. 1989 Endothelium-derived nitric oxide: Actions and properties. FASE B I ., 3:31-36.

I gnarro, L.J ., G.M. Buga, K.S. Wood, R.E. Byrns, and G. Chaudhuri 1987 Endothelium-derived relaxin factor produced and released from artery and vein is nitric oxide. Proc. Natl. Acad. Sci. USA, 84:9265-9269.

Kubes, P., and D.N. Granger 1992 Nitric oxide modulates microvascuIar permeability. Am. J. Physiol., 262:H611-H615.

Lamas, S., P.A. Marsden, K.L. Gordon, P. Tempst, and T. Michel 1992 Endothelial nitric oxide synthase: Molecular cloning and characterization of a distinct constitutive isoform. Proc. Natl. Acad. Sci. USA, 89:6348-6352.

Loesch, A., P. Bodin, and G. Burnstock 1991 Colocalization of endothelin, vasopressin and serotonin in cultured endothelial cells of rabbit aorta. Peptides, 12:1095-1103.

MacCumber, M.W., C.A. Ross, B.M. Glaser, and S.H. Snyder 1989 Endothelin: Visualization of mRNAs by in situ hybridization provides evidence for local action. Proc. Natl. Acad. Sci. USA, 86:7285-7289.

Marchetti, C. A Calligaro, A. Di Nucci, A I caro Cornaglia, S. Rosso, S. Serafini, and F. Piovella 1995 Comparative immunocytochemical localization of von Willebrand factor and P-selectin in lymphatic vessel wall and in cultured lymphatic endothelial cells. Eur. J. Histochem., 39:66.

Marsden, P.A., K.T. Schappert, S. Chen Hai, M. Flowers, C.L. Sundell, J.S. Wilcox, S. Lamas, and T. Michel 1992 Molecular cloning and characterization of human endothelial nitric oxide synthase. FEBS Lett., 307:287-293.

Masaki, T., M. Yanagisawa, and K. Goto 1992 Physiology and pharmacology of endothelins. Med. Res. Rev., 12:391-421.
Moncada, S. 1992 The L-arginine:nitric oxide pathway. Acta Physiol. Scand., 145:201-227.

Moncada, S., and A. Higgs 1993 The L-arginine-nitric oxide pathway. N. Engl. J . Med., 329:2002-2012

Moncada, S., R.M.J. Palmer, and E.A. Higgs 1991 Nitric oxide: Physiology, pathophysiology and pharmacology. Pharmacol. Rev. 43:109-142.

Nakamura, S., M. Naruse, K. Naruse, H. Demura, and H. Uemura $1990 \mathrm{Immunocytochemical} \mathrm{localization} \mathrm{of} \mathrm{endothelin} \mathrm{in} \mathrm{cultured}$ bovine endothelial cells. Histochemistry, 94:475-477.

Ohhashi, T. 1993 Mechanisms for regulating tone in lymphatic vessels. Biochem. Pharmacol., 45:1941-1946.

Ohhashi T., and N. Takahashi 1991 Acetylcholine-induced release of endothelium derived relaxing factor from lymphatic endothelial cells. Am. J. Physiol., 260:H 1172-H1178.

Ohhashi, T., and S. Yokoyama 1994 Nitric oxide and the lymphatic system. J ap. J. Physiol., 44:327-342.

Ohhashi, T., T. Azuma, and M. Sakaguchi 1980 Active and passive mechanical characteristics of bovine mesenteric lymphatics. Am. J. Physiol., 239:H88-H 95.

Ohkuma, M. 1991 The presence of endothelin in the human skin Iymphatic. Progress in Lymphology XIII. Cluzan RV et al., eds. Excerpta Medica (Amsterdam), pp. 91-92.

Palmer, R.M.J., A.G. Ferrige, and S. Moncada 1987 Nitric oxide rel ease accounts for the biological activity of endothelium-derived relaxing factor. Nature, 327:524-526.

Polak, J .M., and S. Van Noorden 1986 I mmunocytochemistry. Modern Methods and Applications. Wright, Bristol.

Resink, T.J ., A.W. Hahn, T. Scott-Burden, J . Powell, E. Weber, and F.R. Buhler 1990 Inducible endothelin mRNA expression and peptide secretion in cultured human vascular smooth muscle cells. Biochem. Biophys. Res. Commun., 168:1303-1310.

Rubanyi, G.M., and L.H. Parker Botel ho 1991 Endothelins. FASEB J ., 5:2713-2720.

Sexton, A.J. . A. Loesch, M. Turmaine, S. Miah, and G. Burnstock 1995 Nitric oxide and human umbilical vessels: Pharmacological and immunohistochemical studies. Placenta, 16:277-288.

Springall, D.R., P.W. Howarth, H. Counihan, R. Djukanovic, S.T. Holgate, and J.M. Polak 1991 Endothelin immunoreactivity of the airway epithelium is elevated in asthmatic patients. Lancet, 337:697-701.

Springall, D.R., V. Riveros Moreno, L. Buttery, A. Suburo, A.E. Bishop M. Merrett, S. Moncada, and J.M. Polak 1992 Immunological detection of nitric oxide synthase(s) in human tissues using heterol ogous anti bodies suggesting different isoforms. Histochemistry, 98:259-266.

Vane J .R., Anggard E.E., Botting R.M. 1990 Regulatory functions of the vascular endothelium. N. Engl. J . Med., 323:27-36.

Yanagisawa, M., H. Kurihara, S. Kimura, Y. Tomobe, M. Kobayashi, Y. Mitsui, Y. Yazaki, K. Goto, and T. Masaki 1988 A novel potent vasoconstrictor peptide produced by vascular endothelial cells. Nature, 332:411-415.

Yoshizawa, T., D. Shini, A. Giaid, M. Yanagisawa, S. Gibson, S. Kimura, Y. Uchiyama, J .M. Polak, T. Masaki, and I. Kanazawa 1990 Endothelin: A novel peptide in the posterior pituitary system. Science, 247:462-464. 